\title{
Effect of Initial Panel Slenderness on Efficiency of Strengthening- By-Stiffening using FRP for Shear Deficient Steel Beams
}

\author{
Tuna Ulger ${ }^{1}$, \\ Ayman M. Okeil 2,* \\ ${ }^{1}$ Research Assistant, Dept. of Civil and Env. Engineering, Louisiana State University, Baton Rouge, LA \\ 70803, USA. Tel.: +1 (225) 578-8442, Email: tulger1@lsu.edu \\ ${ }^{2}$ Professor, Dept. of Civil and Env. Engineering, Louisiana State University, Baton Rouge, LA 70803, \\ USA. Tel.: +1 (225) 578-7048, Fax:+1 (225) 578-4945, Email: aokeil@1su.edu \\ * Corresponding author
}




\section{Effect of Initial Panel Slenderness on Efficiency of Strengthening-By-Stiffening using FRP for Shear Deficient Steel Beams}

\section{ABSTRACT}

The need for strengthening steel structures is as important as it is for concrete structures, or any other aging structure. Strengthening concrete structures by externally bonding thin composite materials in the form of laminates or strips has proven to be an efficient way for enhancing the flexural, shear, and axial strength of deficient elements. Use of external bonding of thin composite material to strengthen steel structures can also be found in literature. This paper presents another effective strengthening technique in which pultruded GFRP sections are bonded to shear deficient regions to enhance the local buckling resistance of thin walled steel structures. Three steel beams with different web thicknesses were tested experimentally with and without GFRP stiffeners to study the efficiency of the new technique; Strengthening-ByStiffening or SBS. The ultimate shear capacities of the beams were enhanced by a minimum of $30 \%$ when one stiffener was used on a beam with a square panel and a maximum of $40 \%$ for beams with larger rectangular panel with two stiffeners (one on each side). The initial global stiffness was also enhanced between 5 and $41 \%$ for the strengthened beams as a result of the externally bonding the GFRP stiffeners. Unlike the one stiffener configuration which experienced a major load drop at high load levels, the post yielding behavior of the two stiffener configuration exhibited a sustainable load capacity around the peak load without any major load drop. Strain reading from the top and bottom flanges at the loading point revealed that a sway frame mechanism became the main shear resisting mechanism after the critical panel buckled due to shear.

Keywords: steel structure; GFRP; shear failure; composite; strengthening, external bonding 

NOMENCLATURE

$L \quad$ length of the beam

$h \quad$ height of steel web

$t_{w} \quad$ thickness of steel web

$P \quad$ applied load on the control panel

$\Delta \quad$ vertical displacement at the load line

$E_{f} \quad$ flexural Modulus of Elasticity

$E_{a} \quad$ axialModulus of Elasticity

$\sigma_{y} \quad$ yield strength

$\sigma_{u} \quad$ ultimate strength

$\varepsilon_{u} \quad$ ultimate strain

$K_{i} \quad$ initial stiffness

$\mu \quad$ sample mean

$\sigma \quad$ standard deviation of a sample

$C_{v} \quad$ coefficient of variation

\section{INTRODUCTION}

The high cost of replacing aging structures drives owners to look for more feasible and economical solutions. Therefore, retrofitting existing structures has become the most common and practical solution to enhance the minimum strength and serviceability limits for aging structures. Retrofitting also addresses sustainability by extending the service life of existing 
Effect of Initial Panel Slenderness on Efficiency of Strengthening-By-Stiffening using FRP for Shear Deficient Steel Beams structures without the need to invest unavailable larger capital resources for a new structure. Thus, existing structures can be utilized for a longer period, and the need for recycling it is delayed resulting in the use of smaller amounts of materials with lesser carbon footprint [1].

Composite materials such as fiber reinforced polymers (FRP) are well suited for retrofitting concrete structures because of their superior mechanical properties relative to traditional construction materials (e.g. concrete) in addition to being light weight and corrosion resistant. In the United States, ACI 440.2R-08 [2] provides guidance for the design of externally bonded FRP systems for strengthening concrete structures. Several other guidelines and codes have also been published around the world [3-6].Strengthening steel structures using externally bonded FRP systems is relatively new when compared to traditional strengthening techniques (i.e. steel plate welding and concrete jacketing) and is lagging behind FRP applications for strengthening concrete structures. Advanced manufacturing technologies of FRP systems allowFRP fibers to be woven within a matrix to form various structural shapes such as I- and Tshapes. FRP structural shapes have the advantage of offering out of plane resistance in addition to the typically utilized in-plane resistance of thin FRP products such as sheets and laminates. The out-of-plane resistance of pultruded FRP sections was first used to stiffen thin walled steel beams by Okeil, et al. [7] as a pilot study, and the ultimate shear resistance increased by $56 \%$ when the pultruded GFRP stiffeners were bonded to the web. The strengthening technique whereby pultruded FRP shapes are used as stiffeners to steel plates in thin-walled beams will be referred to as Strengthening-By-Stiffening, or SBS.

In this paper, an experimental program to investigate the effect of web slenderness and shear panel's aspect ratio on the efficiency of the SBS technique is first described. Three thin- 
Effect of Initial Panel Slenderness on Efficiency of Strengthening-By-Stiffening using FRP for Shear Deficient Steel Beams walled steel beams with two different panel aspect ratios and web thicknesses employing the SBS technique were tested to failure. Resultsfrom the conducted tests are then presented, and finally, conclusions are drawn based on the findings from the presented results and discussions.

\section{COMPOSITE STRENGTHENING}

External bonding of FRP composites is an accepted strengthening technique for concrete structures As is evident by the many successful applications reported in the literature [8, 9]. In comparison, traditional strengthening techniques (e.g. post tensioning bolting of additional steel plates) still account for the vast majority of the strengthening jobs of steel structures. The same can be said about research in both strengthening arenas as well. A quick search shows that the published work on FRP strengthening of concrete structures is about three times that of steel structures. Therefore, there is a need to fill the knowledge gaps on the use of FRP for strengthening steel structures before any design guidelines can be established, which is the first step towards acceptance and use in field applications.

Increasing the ultimate load carrying capacity is mainly the primary objective for strengthening applications, which is often accompanied by loss of ductility [7]. A more ductile performance was observed when GFRP (Glass FRP) or KFRP (Kevlar FRP) were used for strengthening reinforced concrete structures [10], however, the required amount of FRP is typically larger than the amount of CFRP (Carbon FRP) [10,11]. Published work shows that the most widely used composite material for strengthening steel structures is the CFRP sheet/strips with some efforts recommending high or ultra-high modulus CFRP for strengthening steel structures $[12,13]$. This is due to the higher elastic modulus of CFRP as opposed to other types of 
Effect of Initial Panel Slenderness on Efficiency of Strengthening-By-Stiffening using FRP for Shear Deficient Steel Beams composites (e.g. GFRP) makes it more compatible with the mechanical properties of steel. For example, the flexural strengthening of the steel sections were studied experimentally and numerically utilizing different forms and layers of CFRP composites on the tension side of the steel girders [11, 14-17]. In addition to the flexural strengthening efforts, researchers also investigated the feasibility of using composite materials to strengthen steel structures subjected to axial and shear forces. Different steel joint types (e.g. K and V) subjected to the axial forces were also strengthened by wrapping different number of CFRP composite layers [18-20]. A limited number of experiments investigating shear strengthening of steel structures using composites were conducted bonding different form CFRP composites in different configurations $[21,22]$.

The concept in these conventional techniques is the utilization of in-plane resistance of an external reinforcing material, which quickly revealed that the efficiency is less than that observed in strengthening concrete structures due to the large amount of FRP needed for strengthening steel structures $[11,18]$. In the proposed SBS technique, a different form of composite materials; pultruded FRP sections, is utilized in aninnovative way resulting in a practical strengthening technique while reducing the amount of FRP usage.

\section{PROPOSED STRENGHTENING TECHNIQUE}

The main concept behind the proposed SBS technique is the utilization of pultruded FRP sections to enhance the capacity of shear deficient thin-walled steel structures. Fig. 1 shows an illustration of how a wide-flanged pultruded FRP section can be bonded to a thin, buckling-prone steel plate. The enhancement in shear resistance is caused mainly by delaying buckling of the 
Effect of Initial Panel Slenderness on Efficiency of Strengthening-By-Stiffening using FRP for Shear Deficient Steel Beams steel plate as a result of the additional out-of-plane stiffness provided by the pultruded FRP section. Therefore, this stiffening method allows using cheaper, low-modulus fibers within the matrix resins of the composite section to strengthen steel structures whose elastic modulus is inherently higher. SBS success stems from the fact that the flexural rigidity, $E I$, of the additional stiffener is an order of magnitude higher than that of the deficient steel plate. The first preliminary study on using the SBS technique was conducted by Okeil, et al. [23], and more technical details can be found elsewhere[7].

\section{EXPERIMENTAL PROGRAM}

An experimental program was designed to study the effect of initial web slenderness on the efficiency of SBS in enhancing the shear strength of thin-walled steel beams. The program consisted of eight beam specimens with different web thicknesses, shear panel dimensions, and FRP stiffener configuration. Varying the web thickness directly affects the web slenderness, and the shear panel's dimensions directly affect the compression field and hence the beam's shear strength. Finally, the FRP stiffener configuration determines the additional stiffness provided by the pultruded FRP sections.

The following sections describe the specimens and the experimental setup in detail.

\subsection{Beam Specimens}

The tested specimens were first designed to be shear critical by overdesigning for other modes of failure (e.g. flexure, lateral torsional buckling). Finite element models were built to assist in the design process and in predicting modes of failure and loads. The final design was then especially fabricated for the project as a built-up I-shaped section using A36 steel. The mechanical 
Effect of Initial Panel Slenderness on Efficiency of Strengthening-By-Stiffening using FRP for Shear Deficient Steel Beams properties of the steel sections were obtained from uniaxial coupons and are given in Table 1. The two nominal web thicknesses considered in these tests were $3.2 \mathrm{~mm}$ [1/8 in.] and $4.0 \mathrm{~mm}$ [5/32 in.]. While the choice for such thin webs was mainly due to maximum applied load limitations in the available structural testing facilities, it was also justifiable for the goals of the project for two reasons. First, shear deficiency may be due to uniform corrosion of the web plate, which often leads to a reduction in the thickness of structurally sound plates. The other reason is the potential of using SBS as a mean for optimizing thin-walled steel sections by reducing steel plate thickness and complementing its stiffness by bonding pultruded FRP sections during the fabrication process in lieu of welding steel stiffeners and its associated disadvantages. Square and rectangular shear panels were considered. The dimensions of the square panel were $518 \mathrm{x}$ $521 \mathrm{~mm}\left[20^{3 / 8} \times 20^{1 / 2}\right.$ in. $]$ resulting in a nominal aspect ratio equal to 1.0 . The rectangular panel specimens were of the same depth, but wider $\left(772 \mathrm{~mm}\left[30^{3 / 8} \mathrm{in}.\right]\right)$ leading to a nominal aspect ratio of 1.5. The T-shaped FRP stiffeners were obtained from commercially available wideflanged I-shaped sections [6x6x3/8 in.] by cutting one of the two flanges. The remaining flange would serve as the bonding surface with the steel plate. Length-wise, the FRP stiffeners were cut to $482.6 \mathrm{~mm}$ [19 in.] long pieces, which is short of covering the entire depth of the web to avoid the weld seam between the flange and the web. The width of the bonding flange was reduced to $76 \mathrm{~mm}$ [3 in.] for square panel specimens. Control beams, i.e. without any strengthening FRP stiffeners, were also tested.

The following designation system was used for easier reference to the specimens. The first two characters indicated whether the specimen had square shear panels (SB) or rectangular ones (RB) corresponding to the 1.0 and 1.5 panel aspect ratios, respectively. This was followed 
Effect of Initial Panel Slenderness on Efficiency of Strengthening-By-Stiffening using FRP for Shear Deficient Steel Beams by a fraction representing the nominal web thickness in inches in square parenthesis; i.e. [1/8] and [5/32]. The last part of each specimen designation described the FRP stiffener configuration. A ' 0 ' indicated that no stiffeners were used for this specimen; i.e. control, ' 1 ' indicates that only one stiffener was bonded to one side of the web, and finally ' 2 ' indicates that two stiffeners were bonded to the shear panel; one on each side. For example, $\mathrm{SB}[1 / 8]-2$ is a square panel specimen with a 3.2 mm-thick [1/8 in.-thick] web strengthened with two FRP stiffeners, whereas $\mathrm{RB}[5 / 32]-0$ is the control for rectangular panel configurations with $4.0 \mathrm{~mm}$-thick [5/32 in.-thick] web specimens.

The test matrix of the tested beam can be seen in Table 2. The table also lists the slenderness of the beams' webs, which is defined as a ratio of the web height, $h$, to the web thickness, $t_{w}$.

\section{MATERIAL PROPERTIES}

\subsection{Pultruded GFRP Section}

The proposed stiffening technique enhances the strength of the thin walled steel structure significantly by using low modulus pultruded GFRP composites [23]. The same stiffening technique can be employed using high modulus pultruded FRPsections (e.g. CFRP); however, the use of high modulus FRPs is not necessary for this strengthening technique because all failure modes were observed to occur at the bonding interface in the preliminary investigations Okeil, et al. [7]. The pultruded FRP sectionsare mainly utilized to enhancethe out-of-plane resistance of deficient plates in buckling prone regions. Even though the elastic modulus of 
Effect of Initial Panel Slenderness on Efficiency of Strengthening-By-Stiffening using FRP for Shear Deficient Steel Beams GFRP is lower than that of steel, the flexural rigidity, EI, is higher due to the additional stiffness provided by the pultruded GFRP sections.

The pultruded GFRP sections used in this study are commercially available in wide flange beam forms. $\left(\mathrm{EXTERN}^{\circledR} 500\right.$, and PROForm ${ }^{\circledR} \mathrm{WF}$ used for square and rectangular panel beams, respectively). As stated earlier, the chosen $6 \times 6 \times 3 / 8$ wide flange pultruded FRP section was modified to obtain the T-shaped stiffener by cutting one of the flanges. The mechanical properties of pultruded GFRP are listed in Table 3.

\subsection{Adhesive Type and Properties}

Only one adhesive type was used for this study, which is a general purpose bonding agent that is commonly used in strengthening applications of concrete structures for bonding external composite materials. Even though the nature of SBS demands on the adhesive interface between the steel plate and the FRP stiffener are different than the demands in typical strengthening applications, the same adhesive was still chosen because it was shown that it is still effective for SBS applications [23]. The adhesive (Tyfo ${ }^{\circledR} \mathrm{S}-$ Fyfe Co) is a two-component chemical that is mixed at a specific ratio as per the manufacturer's instructions. Fumed silica was added to the resulting mix and stirred for at least 5 minutes to achieve uniform consistency and a workable viscosity. The mechanical properties of the selected adhesives are given in Table 4.

It should be noted that other adhesives that are more suitable for bonding composites to metals can be used. Okeil, et al. [24] compared the performance of two types of adhesives in a recent study, where it was revealed that adhesive with ductile properties perform better in steel strengthening applications. 


\section{Effect of Initial Panel Slenderness on Efficiency of Strengthening-By-Stiffening using FRP for Shear Deficient Steel Beams \\ 6. BONDING PROCESS}

Several surface preparation techniques may be required such as prevention of the galvanic corrosion between the steel/FRP surfaces if different types of FRP are in consideration. Since debonding has been found to be the critical mode of failure in previous investigations [23], the bonding procedure requires utmost care. Furthermore, it is reported that the short and long term durability of the bond is increased with the proper pretreatment of the substrates [25]. In general, FRP surface treatment requires less effort than the steel surface treatment [26]. The FRP's glazed finish was removed by scratching the outer matrix layer to create a rougher surface that is more suitable for bonding. All residual particlesresulting from this stepwere cleaned using a solvent (i.e. acetone) before the adhesive was applied. The other bond side; i.e. steel plate surface, could be treated with a chemical etchants to reach the higher durability level; however, the high curing temperature and the environmental hazard of many etchants limits the application of this treatment [27]. Instead, another feasible and effective method for steel surfaces was employed. Mechanical surface treatment (i.e. grit blasting or sanding) creates a roughened steel surface, into which the adhesive penetrate and createsa mechanical bond [25] in addition to the chemical adhesion. In this study, mechanical surface treatment was used to prepare the steel surfaces in three steps: (1) removing the contaminants from the steel surface, (2) sanding the steel surface by poly abrasive wheel and sanding papers until a white texture appears [12], (3) wiping the revealed white metal surface with a cleaning solvent right before the bonding process.

After the steel and FRP surfaceswere completely freed from any contaminants, rust or particles with a proper surface treatment, the adhesive was applied to the clean and roughened FRP and steel surfaces. A small amount of pressurewas applied on the FRP section until the 
Effect of Initial Panel Slenderness on Efficiency of Strengthening-By-Stiffening using FRP for Shear Deficient Steel Beams adhesive could be seen filling the entire interfacial bond area between the two materials. The goal was to have a thin uniform adhesive layer (about $2 \mathrm{~mm}$-thick [5/64 in.-thick) to avoid the brittle failure [26]. The leftover adhesive was scraped from the steel web to avoid increasing the strength of the steel plate inadvertently by increasing the plate's thickness when the leftover adhesive hardens.

\section{EXPERIMENTAL SETUP}

All beam specimens were tested in three-point bending. The load was applied over the first internal stiffener to create high shear demand on the critical test panel. In Fig. 2 (a) and (b), typical beam specimen showing the main dimensions and location of the applied load are provided. As stated earlier, this configuration ensures that the expected failure mode will be shear buckling of the first panel. It should be noted that due to laboratory difficulties, Specimen $\mathrm{SB}[1 / 8]-1$ was tested with a shorter span length equal to the length of 3 square panels ( $L=1654 \mathrm{~mm}[65.13 \mathrm{in}])$ versus the typical one for SB specimens of 4 panels $(L=2172 \mathrm{~mm}$ [85.50 in.]).

Early analytical and experimental results verified that buckling occurs within the first stiffened panel[28]. Diagonal and vertical FRP stiffener orientations were considered and compared in these pilot studies, and the vertical FRP orientation was found to perform in a more ductile manner than diagonal FRP orientation [23]. Therefore, the pultruded FRP stiffeners were bonded vertically in the middle of thecritical panel. Control specimens were tested without any external FRP stiffener. The strains in the stiffened beam specimens were recorded at the applied load location where the maximum moment occurs. A total of four strain gages were attached to 
Effect of Initial Panel Slenderness on Efficiency of Strengthening-By-Stiffening using FRP for Shear Deficient Steel Beams the beam specimen at the section where the load was applied. Two strain gauges were placed at each of the top and bottom flanges (top and bottom surface of each flange). The locations of the strain gages can be seen in Fig. 2 (b) and Fig. 3, whichshows two cross sections for the control specimen and for a beam strengthened with stiffeners on both sides; i.e., with and without SBS. The choice of the strain gage location is based on previous experience to capture sway-frame action after shear panel buckling [23]. In addition to strains, the data acquisition system recorded readings from a load cell that measures the applied load and an LVDT displacement at the loading location.

\section{RESULTS AND DISCUSSION}

The experimental results are presented in this section for the tested specimens. Load-deflection curves from recorded LVDT and load cell readings will be first presented. Strain readings at the section under the load will then be discussed with emphasis on shear panel buckling identification and the distinct behavioral shift pre- and post-buckling.

\subsection{Load-deflection Curves}

The load-deflection curvesfor all square panel specimens $\mathrm{SB}[1 / 8]$ are plotted in Fig. 4.The three shown curves are for the control SB [1/8]-0 and strengthened specimens, with one stiffener $\mathrm{SB}[1 / 8]-1$ and two stiffeners SB[1/8]-2. The flange width of the FRP T-shaped stiffener was 76.2 mm-wide [3 in.-wide.] for the strengthened specimens in this group. The ultimate load capacities of SB[1/8] beams are given in Table 5 for the stiffened and unstiffened cases, and it can be seen that load capacities increased $30 \%$ and $34 \%$ for one and two stiffener cases, respectively. The yield load (identified as the end of the proportional limit) also increased with the number 
Effect of Initial Panel Slenderness on Efficiency of Strengthening-By-Stiffening using FRP for Shear Deficient Steel Beams stiffeners which can be seen in Fig. 4. Furthermore, it can be seen that the maximum load was reached in a gradual increase after yielding for the specimen with one stiffener, while a clear plateau was observed for the beam with two stiffeners. This behavior may be attributed to the following two reasons. First, the adhesive layer is subjected to different stress states on opposite sidesof the web. If the buckling wave causes the web to bulge such that the adhesive layer on one side is subjected to tension as the FRP stiffener is forced to separate from the steel web, the adhesive on the opposite side will be under compression between the FRP and steel surfaces. This behavior is illustrated in Fig. 5. It is known that the compression resistance of the adhesives is higher than its tension and shear resistance[29, 30], and the tensile stresses cause the failure of the adhesives while the shear stresses cause excessive deformation without failure [29]. Hence, even if the adhesive interface gets damaged on the tension side of a beam with two opposite stiffeners, the opposite side would still be intact and keep the panel stiffness. Laboratory observations confirmed that the adhesive failed locally on tension side, while the adhesive on the compression side remained intact.Fig. 4 also showsa load drop at higher load levels for the one stiffener case, which confirms that localized adhesive failure takes place at higher load levels. It can be seen that the load drop for the one stiffener configuration is not as pronounced for the two opposite stiffener specimen. The second reason for having a clear plateau for the specimen with two opposite stiffeners isthat the additional stiffness provided by the FRP stiffener and adhesive layer on both sides of the web panel, which ensures that the panel's behavior will be closer to a split panel than in the case of one-sided stiffener. Thus allowing for more plasticization of the less slender web plate. 


\section{Effect of Initial Panel Slenderness on Efficiency of Strengthening-By-Stiffening using FRP for Shear Deficient Steel Beams}

The load deflection behavior for the rectangular panel beamspecimens with $3.2 \mathrm{~mm}[1 / 8$ in] web thickness, $\mathrm{RB}[1 / 8]$ is similar to that for $\mathrm{SB}[1 / 8]$ beam specimens as can be seen in Fig. 6 . The FRP stiffener's flange width for this group was $152 \mathrm{~mm}$ [6 in.] and the panel aspect ratio was $1: 1.5$. The ultimate failure load for the stiffened specimens increased by $30 \%$ and $36 \%$ for the $\mathrm{RB}[1 / 8]-1$ and of $\mathrm{RB}[1 / 8]-2$ cases, respectively.The third group of specimens with thicker web (4.0 mm [5/32 in.]) exhibited a 40\% load capacity increase as a result of SBS. As can be seen in Fig. 7, the $\mathrm{RB}[5 / 32]-2$ specimen resistance to the applied load did not drop suddenly indicating that a major loss of bond between the FRP stiffeners and the steel web never took place. The test procedure was stopped when the stroke of the test machine reached the designated deflection limit. A similar limit was also set for Specimens SB[1/8]-2 and RB[1/8]-2. Fig. 8 shows the critical panel for Specimen $\mathrm{RB}[1 / 8]-1$ after failure. One can see that after complete debonding of FRP section, the web buckled in a single wave along the tension field of the critical panel.

\subsection{Initial Global Stiffness}

In addition to enhancing the load capacity, SBS can also enhance the global stiffness of strengthened beams. The initial stiffness value, $K_{i}$, is defined as an initial slope of load-deflection curve. The $K_{i}$ values of the tested beams increased after the introduction of SBS and stiffnesses for specimens with two stiffeners were higher than those with only one stiffener. As expected, the increase in stiffness for the SB[1/8]-1 specimen was more than the stiffness increase of $\mathrm{SB}[1 / 8]-2$ as a result of the aforementioned different span lengths at which this group was tested. Therefore, the $4 \%$ difference between the initial stiffnesses of SB[1/8]-1 and SB[1/8]-2 does not 
Effect of Initial Panel Slenderness on Efficiency of Strengthening-By-Stiffening using FRP for Shear Deficient Steel Beams reflect the proportional increase as the number of stiffener increases. The effect of using two opposite stiffeners is much clearer for the $\mathrm{RB}[1 / 8]$ specimens. Specimens $\mathrm{RB}[1 / 8]-1$ and $\mathrm{RB}[1 / 8]-2$ show $28 \%$ and $41 \%$ increase in initial stiffness, respectively, compared to the control specimen RB[1/8]-0. Table 5 lists initial stiffness values for all tested cases. In general, it is clear that the effectiveness of the proposed strengthening technique in terms of initial stiffness is more pronounced for beams with higher initial slenderness ratios as they benefit more from the introduction of SBS.

\subsection{Ductility}

With the exception of few applications [31], the use of composite materials to strengthen concrete and steel structures in flexure is known to reduce the ductility of strengthened beams [2]. Even though the proposed failure mode for shear deficient steel structures strengthened using SBS is typically sudden when the debonding occurs at the interface between the GFRP and steel surfaces, a ductile behavior was observed before failure in previous studies [7]. The tested beams showed substantial ductility beyond the yield point up to the debonding of the FRP stiffener, which was usually accompanied by a major load drop. Cracking of the epoxy layers, which sounds like glass shattering, was clearly heard starting around the initiation of yielding. The intensity of the cracking sounds increased as the test progressed further until the entire FRP stiffener debonded. After the tests were completed, the internal epoxy cracks under the debonded GFRP stiffener could be clearly seen. Another possible type of failure was the adhesion failure either at steel or GFRP surfaces. Therefore, both adhesion and cohesion failures should be investigated for SBS applications. 


\section{Effect of Initial Panel Slenderness on Efficiency of Strengthening-By-Stiffening using FRP for Shear Deficient Steel Beams}

\subsection{Strain Readings}

As stated earlier, the tested beams were designed with slender webs to create an elastic buckling mode of failure as per the AASHTO LRFD bridge design specification [32]. Two beams, $\mathrm{SB}[1 / 8]-1$ and $\mathrm{RB}[1 / 8]-2$, were instrumented with strain gauges to measure longitudinal strains in the top and bottom flanges of the steel beams at the loaded section. Table 6 lists the strain readings at the top and bottom surfaces of the top and bottom flanges. The maximum strain readings at the time of web buckling were $0.0563 \%$ and $0.0604 \%$ on the bottom surface of the tension flanges for $\mathrm{SB}[1 / 8]-1$ and $\mathrm{RB}[1 / 8]-2$, respectively. It can be seen from these values that the steel flanges were under elastic stress levels when web buckling initiated. Up to this point, the applied load is transferred through the web panel mainly through a tension field tie.

Strain readings of the rectangular panel beams are plotted in Fig. 9 and Fig. 10 for one and two stiffeners cases, respectively, and the readings followed a similar trendfor both beams. As expected, the top flange gages initially recorded compressive strains and the bottom flange gages recorded tensile strains. The readings start in an almost linear trend with small differences between the top and bottom readings for each flange. This behavior continues until the applied load reached a level that caused buckling initiation. Once the beams were loaded beyond that point, buckling ensues and the strain readings for each flange (top and bottom) start changing in different directions. This is an indication of local bending of each flange. This post buckling behavior is analogous to a sway frame mechanism where plastic joints form on the local members. Fig. 11 shows a schematic of the sway mechanism and local plastic moments at the top and bottom flanges for the tested beams. This is caused by the fact that the beams' resistance to the applied force starts shifting from the tension field tie mechanism to the sway frame 
Effect of Initial Panel Slenderness on Efficiency of Strengthening-By-Stiffening using FRP for Shear Deficient Steel Beams mechanism as the web buckling progresses. Quantifying the portion of the load resisted by each mechanism experimentally is challenging. Therefore, the authors are currently developing finite element models that can be used for this purpose.

\section{CONCLUSIONS}

One square and two rectangular panel beams with two different web slenderness values and web thicknesses were experimentally tested with and without FRP stiffeners. The steel webs of the beams were stiffened by externally bonding vertical pultruded FRP sections in two configurations; one and two stiffeners (one on each side). The proposed strengthening technique, Strengthening-By-Stiffening or SBS, utilizes the out-of-plane resistance of cheaper pultruded FRP sections in contrast to conventional FRP strengthening techniques that rely only in-plane resistance of relatively expensive composite fibers. In the current study, one adhesivetype was used for external bonding, and all failure mechanisms were developed at the bond joint. Built-up I-shaped steel beams were tested monotonically under three-point loading configuration, where the load was applied on the first internal transverse stiffener.

Based on the experimental results, the following can be concluded:

- The proposed SBS method enhances the ultimate failure capacity of the controlled steel beams by up to $40 \%$. The maximum percentage increase in shear resistance happened when two FRP stiffeners were bonded to the web; one on each side.

- The square and rectangular panels that have $3.2 \mathrm{~mm}[1 / 8 \mathrm{in}]$ steel web thicknesses did not experience sudden load drops during the experiments when stiffened with 


\section{Effect of Initial Panel Slenderness on Efficiency of Strengthening-By-Stiffening using FRP for Shear Deficient Steel Beams}

two stiffeners. One stiffener scheme of these beams did not reach the two stiffeners' strength level or almost reached that level but did not maintain this load level for long after buckling. Therefore, two-stiffener strengthening sustain the post yielding behavior of all the stiffened beams. The main reason for this behavior can be attributed to the fact that the resistance of epoxy layers facing each other is different under the tension and compression forces, hence, they complement each other.

- $\quad$ SBS caused the initial global stiffness of the tested steel beams to increase for all tested specimens. Other than the fact that introducing additional stiffness increases the initial global stiffness, a clear correlation between the amount of increase in initial stiffness and the FRP stiffener configuration could not be established.

- Strain readings showed that the load path from the point of application to the supports started in a classical tension field tie manner. Once the web panel buckling initiated, the load transfer shifted to a sway frame mechanism causing local plasticization of the flanges.

In summary, the proposed SBS technique shows promise as an alternative strengthening technique for steel structures that does not require on site welding or bolting. It is capable of achieving substantial capacity gains as shown in this paper. It can be said that SBS is a feasible alternative for strengthening steel beams that may not be initially deficient, but whose slenderness increases over time due to environmental effects, which is especially true for built-up sections typically used in bridge construction whose webs are relatively more slender than hot- 
Effect of Initial Panel Slenderness on Efficiency of Strengthening-By-Stiffening using FRP for Shear Deficient Steel Beams rolled sections. SBS also has the potential of being introduced in the design of new steel beams to achieve lighter sections with thinner webs that are stiffened with FRP stiffeners without the need or welding or bolting.

The presented results warrant further investigations of SBS with special focus on better, more ductile adhesives that are more suitable for steel applications. This can be considered an optimization problem where effective parameters, such as bonding area, out of plane resistance of stiffeners, environmental effects and fatigue life, could be studied to establish a full understanding of the behavior of this new strengthening technique. Another area of future research would be to establish practical design methodologies for SBS.

\section{ACKNOWLEDGMENTS}

This research is sponsored in part by the National Science Foundation (CMMI\#1030575). The donation of Fyfe Co., LLC, and Bedford Reinforced Plastics, Inc., and support from Strongwell Corporation are greatly appreciated. Additional support from Department of Civil and Environmental Engineering at Louisiana State University is also acknowledged. Any opinions, findings, and conclusions or recommendations expressed in this material are those of the authors and do not reflect the views of the sponsoring agencies. 


\section{Effect of Initial Panel Slenderness on Efficiency of Strengthening-By-Stiffening using FRP for Shear Deficient Steel Beams}

\section{REFERENCES}

[1] P. Jones, S. Lannon, J. Patterson, Retrofitting existing housing: how far, how much?, Building Research \& Information, 41 (2013) 532-550.

[2] ACI Committee 440, Guide for the Design and Construction of Externally Bonded FRP Systems for Strengthening Concrete Structures, in: ACI 440.2R-08, American Concrete Institude, Michigan, 2008.

[3] Japan Building Disaster Prevention Association (JBDPA), Seismic Retrofitting Design and Construction Guidelines for Existing Reinforced Concrete (RC) Buildings with FRP Materials, in, Japan, 1999.

[4] The ISIS Canada Research Center, FRP Rehabilitaion of Reinforced Concrete Structures, in: Design Manual No. 4, Quebec, Canada, 2004.

[5] International Concrete Repair Institute, Guide for the Selection of Strengthening Systems for Concrete Structures, in: No. 320.1, Rosemont, IL, 2006.

[6] FIB Bulletin No.14, Externally bonded FRP reinforcement for RC structures, in, 2001.

[7] A.M. Okeil, Y. Bingol, R. Ferdous, Novel Technique for Inhibiting Buckling of Thin-Walled Steel Structures Using Pultruded Glass FRP Sections, Journal of Composites for Construction, 13 (2009) 547-557.

[8] C. Bakis, Bank, L., Brown, V., Cosenza, E., Davalos, J., Lesko, J., Machida, A., Rizkalla, S., and Triantafillou, T., Fiber-Reinforced Polymer Composites for Construction-State-of-the-Art Review, Journal of Composites for Construction, 6 (2002) 73-87.

[9] A. Nanni, Concrete Repair with Externally Bonded FRP Reinforcement, American Concrete Institute, 17 (1995) 22-26.

[10] T. Triantafillou, N. Plevris, Strengthening of RC beams with epoxy-bonded fibre-composite materials, Materials \& Structures, 25 (1992) 201. 
Effect of Initial Panel Slenderness on Efficiency of Strengthening-By-Stiffening using FRP for Shear Deficient Steel Beams

[11] R. Sen, L. Liby, G. Mullins, Strengthening steel bridge sections using CFRP laminates, Composites Part B: Engineering, 32 (2001) 309-322.

[12] D. Schnerch, M. Dawood, S. Rizkalla, E. Sumner, Proposed design guidelines for strengthening of steel bridges with FRP materials, Construction and Building Materials, 21 (2007) 1001-1010.

[13] K. Harries, S. El-Tawil, Steel-FRP Composite Structural Systems, in: Composite Construction in Steel and Concrete VI, American Society of Civil Engineers, 2011, pp. 703-716.

[14] T.C. Miller, M.J. Chajes, D.R. Mertz, J.N. Hastings, Strengthening of a Steel Bridge Girder Using CFRP Plates, Journal of Bridge Engineering, 6 (2001) 514-522.

[15] A.H. Al-Saidy, F.W. Klaiber, T.J. Wipf, Strengthening of steel-concrete composite girders using carbon fiber reinforced polymer plates, Construction and Building Materials, 21 (2007) 295-302.

[16] Y.J. Kim, K.A. Harries, Predictive Response of Notched Steel Beams Repaired with CFRP Strips Including Bomd-Slip Behavior, International Journal of Structural Stability and Dynamics, 12 (2012) 1-21.

[17] K. Galal, H.M. Seif ElDin, L. Tirca, Flexural Performance of Steel Girders Retrofitted Using CFRP Materials, Journal of Composites for Construction, 16 (2012) 265-276.

[18] A. Fam, S. Witt, S. Rizkalla, Repair of damaged aluminum truss joints of highway overhead sign structures using FRP, Construction and Building Materials, 20 (2006) 948-956.

[19] Z.-G. Xiao, X.-L. Zhao, Cfrp Repaired Welded Thin-Walled Cross-Beam Connections Subject to in-Plane Fatigue Loading, International Journal of Structural Stability and Dynamics, 12 (2012) 195-211.

[20] X.Y. Gao, T. Balendra, C.G. Koh, Buckling strength of slender circular tubular steel braces strengthened by CFRP, Engineering Structures, 46 (2013) 547-556.

[21] K. Narmashiri, M.Z. Jumaat, N.H.R. Sulong, Shear strengthening of steel I-beams by using CFRP strips, Scientific Research and Essays, 5 (2010) 2155-2168. 
Effect of Initial Panel Slenderness on Efficiency of Strengthening-By-Stiffening using FRP for Shear Deficient Steel Beams

[22] Y. Okuyama, T. Miyashita, D. Wakabayashi, N. Koide, Y. Hidekuma, A. Kobayashi, W. Horimoto, M. Nagai, Shear Buckling Test For Steel Girder Bonded CFRP On Its Web, in: CICE, International Institute For Frp In Construction, Rome, Italy, 2012, pp. 01-261.

[23] A.M. Okeil, Y. Bingol, M.R. Ferdous, A novel technique for stiffening steel structures, in, Baton Rouge, La. : Louisiana Transportation Research Center, 2009., 2009.

[24] A.M. Okeil, T. Ulger, H. Babaizadeh, Effect of Adhesive Type on Strengthening-ByStiffening for Shear-deficient Thin-walled Steel Structures, International Journal of Adhesion and Adhesives, (2014).

[25] A. Baldan, Adhesively-bonded joints and repairs in metallic alloys, polymers and composite materials: Adhesives, adhesion theories and surface pretreatment, Journal of Materials Science, 39 (2004) 1-49.

[26] K. Harries, M. Dawood, Behavior and Performance of Fiber-Reinforced Polymer-to-Steel Bond, Transportation Research Record, 2313 (2012) 181.

[27] R.F. Wegman, J. Van Twisk, Surface Preparation Techniques for Adhesive Bonding, Elsevier Science, Burlington, 2012.

[28] A.M. Okeil, Y. Bingol, M. Chorkey, Stiffening Thin-Walled Structures Using Pultruded FRP Sections, in: Highways for LIFE and Accelerated Bridge Construction, FHWA Bridge Engineering Conference, Orlando, FL, 2010.

[29] B. Fiedler, M. Hojo, S. Ochiai, K. Schulte, M. Ando, Failure behavior of an epoxy matrix under different kinds of static loading, Composites Science and Technology, 61 (2001) 16151624.

[30] J.D. Littell, C.R. Ruggeri, R.K. Goldberg, G.D. Roberts, W.A. Arnold, W.K. Binienda, Measurement of Epoxy Resin Tension, Compression, and Shear Stress-Strain Curves over a Wide Range of Strain Rates Using Small Test Specimens, Journal of Aerospace Engineering, 21 (2008) 162-173.

[31] Y. Idris, T. Ozbakkaloglu, Flexural behavior of FRP-HSC-steel composite beams, ThinWalled Structures, 80 (2014) 207-216. 
Effect of Initial Panel Slenderness on Efficiency of Strengthening-By-Stiffening using FRP for Shear Deficient Steel Beams [32] AASHTO, LRFD Bridge Design Specifications in, Washington, D.C. , 2004. 
Effect of Initial Panel Slenderness on Efficiency of Strengthening-By-Stiffening using FRP for Shear Deficient Steel Beams

\section{LIST OF TABLES}

Table 1 Mechanical Properties of Steel Material............................................................... 23

Table 2 Experimental Program Test Matrix ................................................................... 24

Table 3 Flexural Properties of FRP Specimens ........................................................ 25

Table 4 Mechanical Properties of Epoxy Material ............................................................ 26

Table 5 Load capacity and initial stiffness increments for tested beams............................... 27

Table 6 Maximum strain readings before the initiation of web buckling................................ 28 
Effect of Initial Panel Slenderness on Efficiency of Strengthening-By-Stiffening using FRP for Shear Deficient Steel Beams

Table 1 Mechanical Properties of Steel Material

\begin{tabular}{|c|c|c|c|c|}
\hline \multicolumn{2}{|c|}{ Steel } & $\begin{array}{c}E_{s}, \mathbf{G P a} \\
{[\mathrm{ksi}]}\end{array}$ & $\begin{array}{c}F_{y}, \mathrm{MPa} \\
{[\mathrm{ksi}]}\end{array}$ & $\begin{array}{c}F_{u}, \mathrm{MPa} \\
{[\mathrm{ksi}]}\end{array}$ \\
\hline \multirow{3}{*}{ 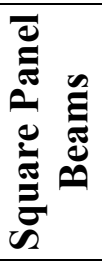 } & $\mu(m e a n)$ & 197 [28594] & $290[42.0]$ & 386 [56.0] \\
\hline & $\sigma(S D)$ & $15.3[2222]$ & $24.1[3.5]$ & $25.5[3.7]$ \\
\hline & $C_{V}(\%)$ & 7.6 & 8.3 & 6.6 \\
\hline \multirow{3}{*}{ 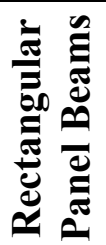 } & $\mu($ mean) & 205 [29798] & $278[40.4]$ & 283 [41.0] \\
\hline & $\sigma(S D)$ & $6.2[901]$ & $32.7[4.74]$ & 18.4 [2.67] \\
\hline & $C_{V}(\%)$ & 3.0 & 11.9 & 6.4 \\
\hline
\end{tabular}


Table 2 Experimental Program Test Matrix

\begin{tabular}{|c|c|c|c|c|c|c|}
\hline \multicolumn{2}{|c|}{ Specimen } & $\begin{array}{c}\text { Nominal Web } \\
\text { Thickness } \\
\text { (mm [in.]) }\end{array}$ & $\begin{array}{c}\text { Panel } \\
\text { aspect } \\
\text { ratio }\end{array}$ & $\begin{array}{l}\text { Width of } \\
\text { FRP flange } \\
(\mathrm{mm}[\mathrm{in}])\end{array}$ & $\begin{array}{c}\text { No. of } \\
\text { FRPstiffeners }\end{array}$ & $\begin{array}{c}\text { Slenderness } \\
\left(h / t_{w}\right)\end{array}$ \\
\hline \multirow{3}{*}{$\mathrm{SB}[1 / 8]$} & 0 & \multirow{3}{*}{$3.2[1 / 8]$} & \multirow{3}{*}{1.0} & \multirow{3}{*}{$76.2[3.0]$} & -- & \multirow{3}{*}{152.0} \\
\hline & 1 & & & & 1 & \\
\hline & 2 & & & & 2 & \\
\hline \multirow{3}{*}{$\mathrm{RB}[\mathbf{1} / \mathbf{8}]$} & 0 & \multirow{3}{*}{$3.2[1 / 8]$} & \multirow{3}{*}{1.5} & \multirow{3}{*}{$152.4[6.0]$} & -- & \multirow{3}{*}{152.0} \\
\hline & 1 & & & & 1 & \\
\hline & 2 & & & & 2 & \\
\hline \multirow{2}{*}{$\mathrm{RB}[5 / 32]$} & 0 & \multirow{2}{*}{$4.0[5 / 32]$} & \multirow{2}{*}{1.5} & \multirow{2}{*}{$152.4[6.0]$} & -- & \multirow{2}{*}{121.6} \\
\hline & 2 & & & & 2 & \\
\hline
\end{tabular}


Effect of Initial Panel Slenderness on Efficiency of Strengthening-By-Stiffening using FRP for Shear Deficient Steel Beams

Table 3 Flexural Properties of FRP Specimens

\begin{tabular}{|c|c|c|c|}
\hline \multicolumn{2}{|c|}{ FRP } & $E_{f}, \mathbf{G P a}[\mathrm{ksi}]$ & $\sigma_{u}, \mathrm{MPa}[\mathrm{ksi}]$ \\
\hline \multirow{3}{*}{ 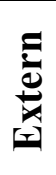 } & $\mu$ (mean) & $13.20[1915]$ & $257[37.3]$ \\
\hline & $\sigma(\mathrm{SD})$ & 1.85 [268] & $44.3[6.4]$ \\
\hline & $C_{V}(\%)$ & 14.0 & 17.1 \\
\hline \multirow{3}{*}{ 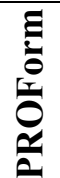 } & $\mu$ (mean) & 24.4 [3536] & $389[56.5]$ \\
\hline & $\sigma(\mathrm{SD})$ & $1.5[216]$ & $27.6[4.0]$ \\
\hline & $C_{V}(\%)$ & 6.1 & 6.9 \\
\hline
\end{tabular}


Effect of Initial Panel Slenderness on Efficiency of Strengthening-By-Stiffening using FRP for Shear Deficient Steel Beams

Table 4 Mechanical Properties of Epoxy Material

\begin{tabular}{lccc}
\hline \multirow{2}{*}{ Tyfo $^{\circledR} \mathbf{S}$} & \multicolumn{3}{c}{ Rate of Loading } \\
& $\mathbf{1 . 2 7} \mathbf{~ m m} / \mathbf{m i n}[\mathbf{0 . 0 5} \mathbf{~ i n} / \mathbf{m i n}]$ \\
\hline \multirow{2}{*}{ (mean) } & $2575[373.5]$ & $30.13[4.37]$ & 1.29 \\
$\sigma(\mathrm{SD})$ & $202[29.32]$ & $1.72[0.25]$ & 0.12 \\
$\mathrm{C}_{\mathrm{V}}(\%)$ & 7.8 & 5.7 & 9.3 \\
\hline
\end{tabular}


Effect of Initial Panel Slenderness on Efficiency of Strengthening-By-Stiffening using FRP for Shear Deficient Steel Beams

Table 5Load capacity and initial stiffness increments for tested beams

\begin{tabular}{cccccc}
\hline Beam Labels & $\begin{array}{c}\text { Failure } \\
\text { Load } \\
\mathbf{k N}[\mathbf{k i p s}]\end{array}$ & $\begin{array}{c}\text { Capacity } \\
\text { Increase }\end{array}$ & $\begin{array}{c}\text { Initial } \\
\text { Stiffness } \\
\mathbf{( k / i n )} \\
\boldsymbol{K}_{\boldsymbol{i}}=\boldsymbol{P} / \Delta\end{array}$ & $\begin{array}{c}\text { Stiffness } \\
\text { Increase }\end{array}$ \\
\hline \multirow{3}{*}{ SB[1/8] } & 0 & $240[54.0]$ & -- & 377 & -- \\
\cline { 2 - 6 } & 1 & $311[70.0]$ & $30 \%$ & 428 & $14 \%$ \\
\hline \multirow{2}{*}{$\mathbf{R B}[\mathbf{1 / 8}]$} & 2 & $322[72.5]$ & $34 \%$ & 413 & $10 \%$ \\
\hline \multirow{2}{*}{$\mathbf{R B}[\mathbf{5 / 3 2}]$} & 0 & $222[50.0]$ & -- & 301 & -- \\
\hline & 1 & $289[65.0]$ & $30 \%$ & 384 & $28 \%$ \\
\hline & 2 & $302[68.0]$ & $36 \%$ & 424 & $41 \%$ \\
\hline
\end{tabular}


Effect of Initial Panel Slenderness on Efficiency of Strengthening-By-Stiffening using FRP for Shear Deficient Steel Beams

Table 6 Maximum strain readings before the initiation of web buckling

\begin{tabular}{lcccc}
\hline \multirow{2}{*}{ Beam } & \multicolumn{2}{c}{ Top Flange } & \multicolumn{2}{c}{ Bottom Flange } \\
& Top Strain & Bottom Strain & Top Strain & Bottom Strain \\
\hline SB[1/8]-1 & $-0.0296 \%$ & $-0.0307 \%$ & $0.0312 \%$ & $0.0563 \%$ \\
\hline RB[1/8]-2 & $-0.0377 \%$ & $-0.0115 \%$ & $0.0251 \%$ & $0.0604 \%$ \\
\hline
\end{tabular}




\section{Effect of Initial Panel Slenderness on Efficiency of Strengthening-By-Stiffening using FRP for Shear Deficient Steel Beams}

\section{LIST OF FIGURES}

Fig. 1 Out-of-plane resistance of pultruded GFRP section (not scaled sketch) ........................ 30

Fig. 2 Typical (a) square and (b) rectangular beam specimen and test set up configurations ...... 31

Fig. 3 Cross-sectional views of the beam specimen with and without FRP stiffener................ 32

Fig. 4 Load vs deflection plot of SB[1/8]-0, SB[1/8]-1, SB[1/8]-2 beams............................. 33

Fig. 5 FRP stiffener failure mechanism at adhesive level (not scaled sketch) ........................ 34

Fig. 6 Load vs deflection plot of RB[1/8]-0, RB[1/8]-1, RB[1/8]-2 beams .......................... 35

Fig. 7 Load vs deflection plot of RB[5/32]-0, RB[5/32]-2 beams ...................................... 36

Fig. 8 Failure mode for Specimen RB[1/8]-1 (a) front - (b) back ....................................... 37

Fig. 9 Strain readings of SB[1/8]-1 at the top and bottom flanges ....................................... 38

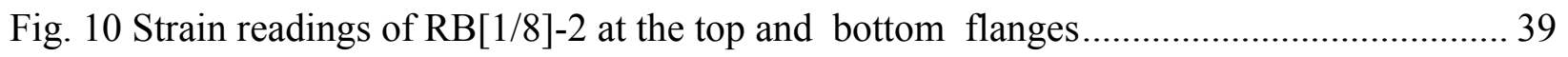

Fig. 11 Sway Frame Action and Local Plastic Moment Locations ........................................ 40 
Effect of Initial Panel Slenderness on Efficiency of Strengthening-By-Stiffening using FRP for Shear Deficient Steel Beams
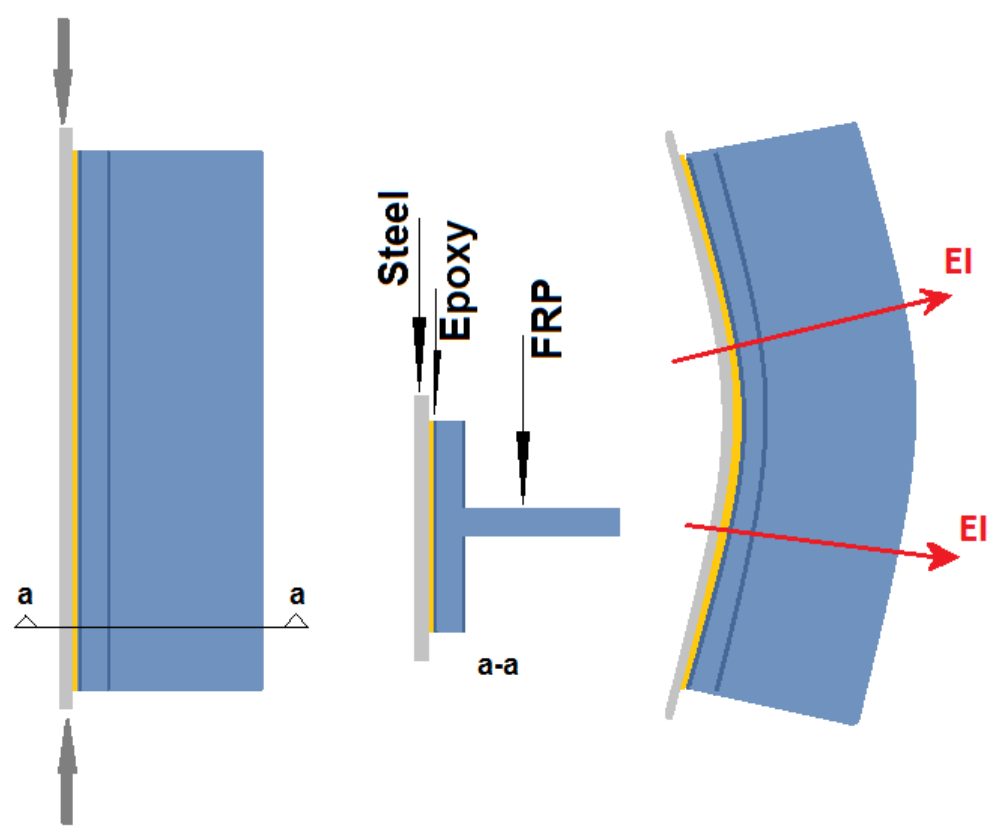

Fig. 1Out-of-plane resistance of pultruded GFRP section (not scaled sketch) 
Effect of Initial Panel Slenderness on Efficiency of Strengthening-By-Stiffening using FRP for Shear Deficient Steel Beams
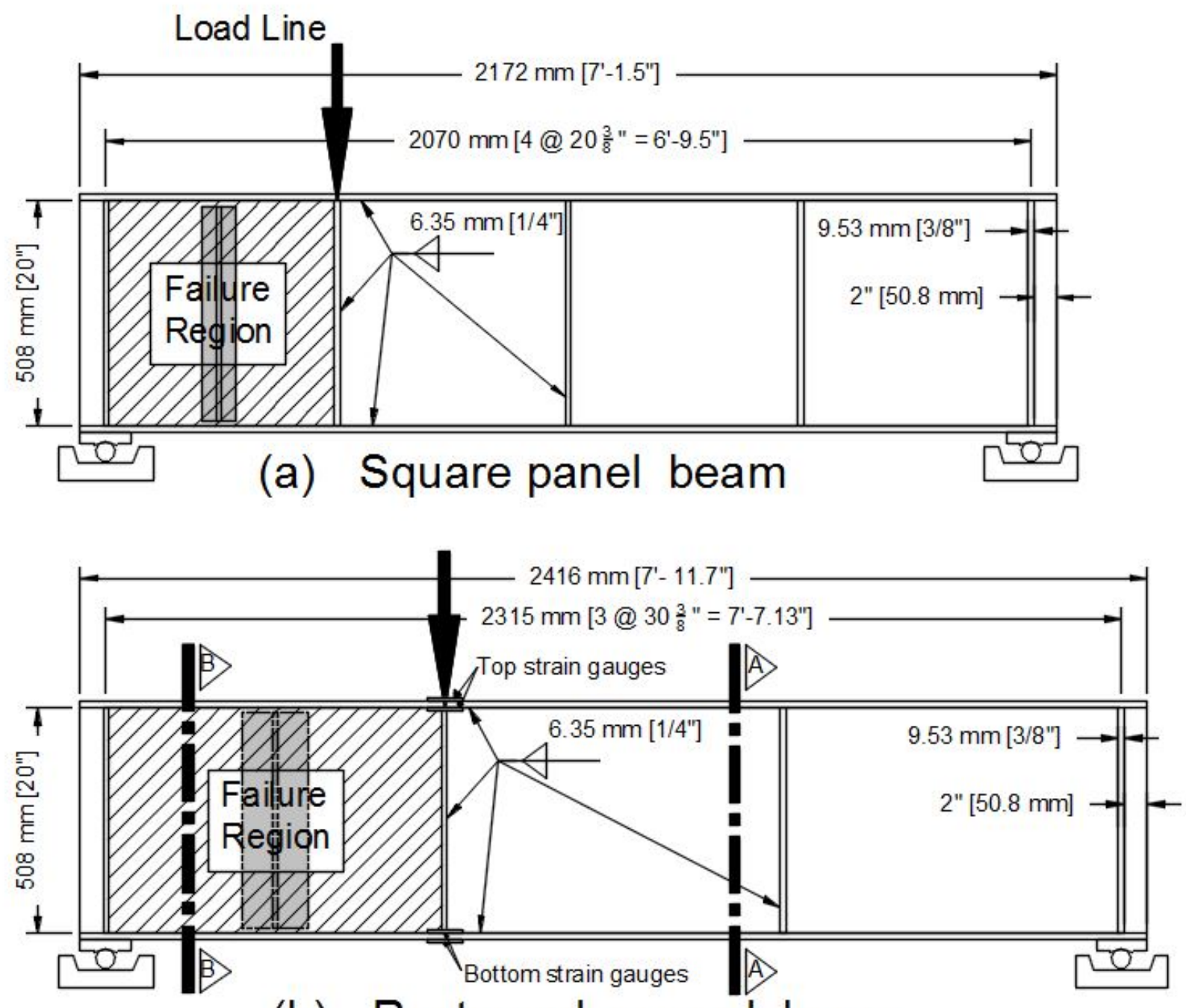

(b) Rectangular panel beam

Fig. 2 Typical (a) square and (b) rectangular beam specimen and test set up configurations 
Effect of Initial Panel Slenderness on Efficiency of Strengthening-By-Stiffening using FRP for Shear Deficient Steel Beams

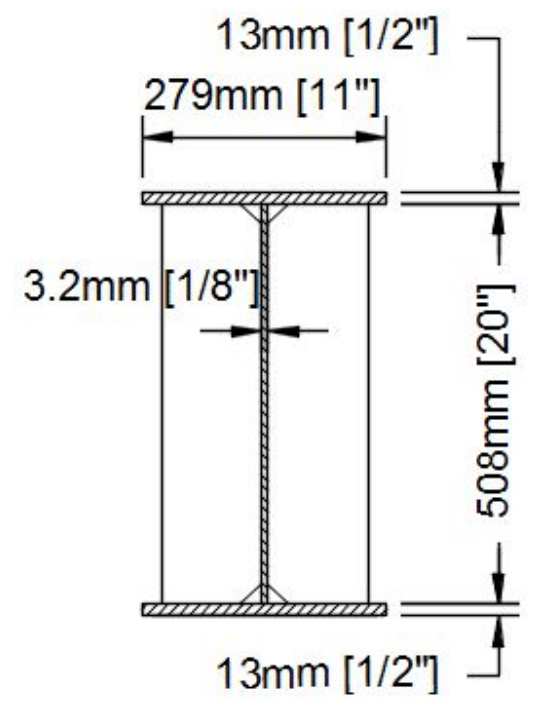

(Section A-A)

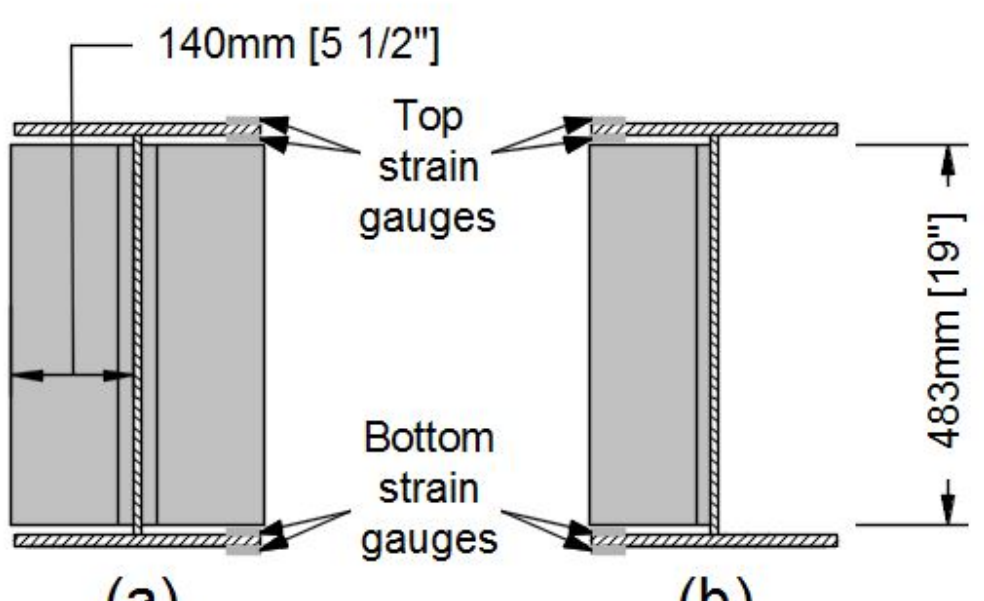

(b) (Section B-B)

Fig. 3Cross-sectional views of the beam specimen with and without FRP stiffener 
Effect of Initial Panel Slenderness on Efficiency of Strengthening-By-Stiffening using FRP for Shear Deficient Steel Beams

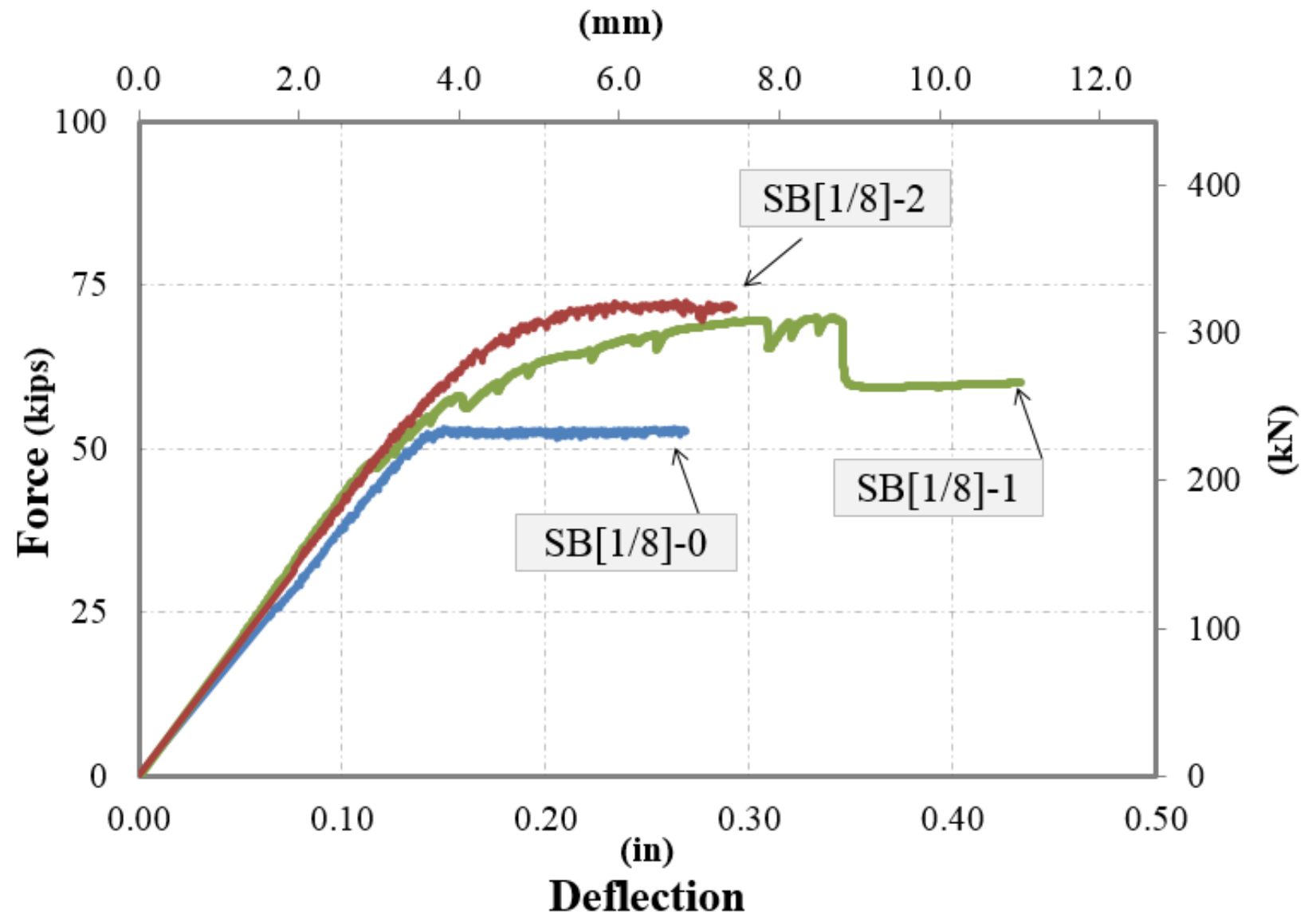

Fig. 4Load vs deflection plot of SB[1/8]-0, SB[1/8]-1, SB[1/8]-2 beams 


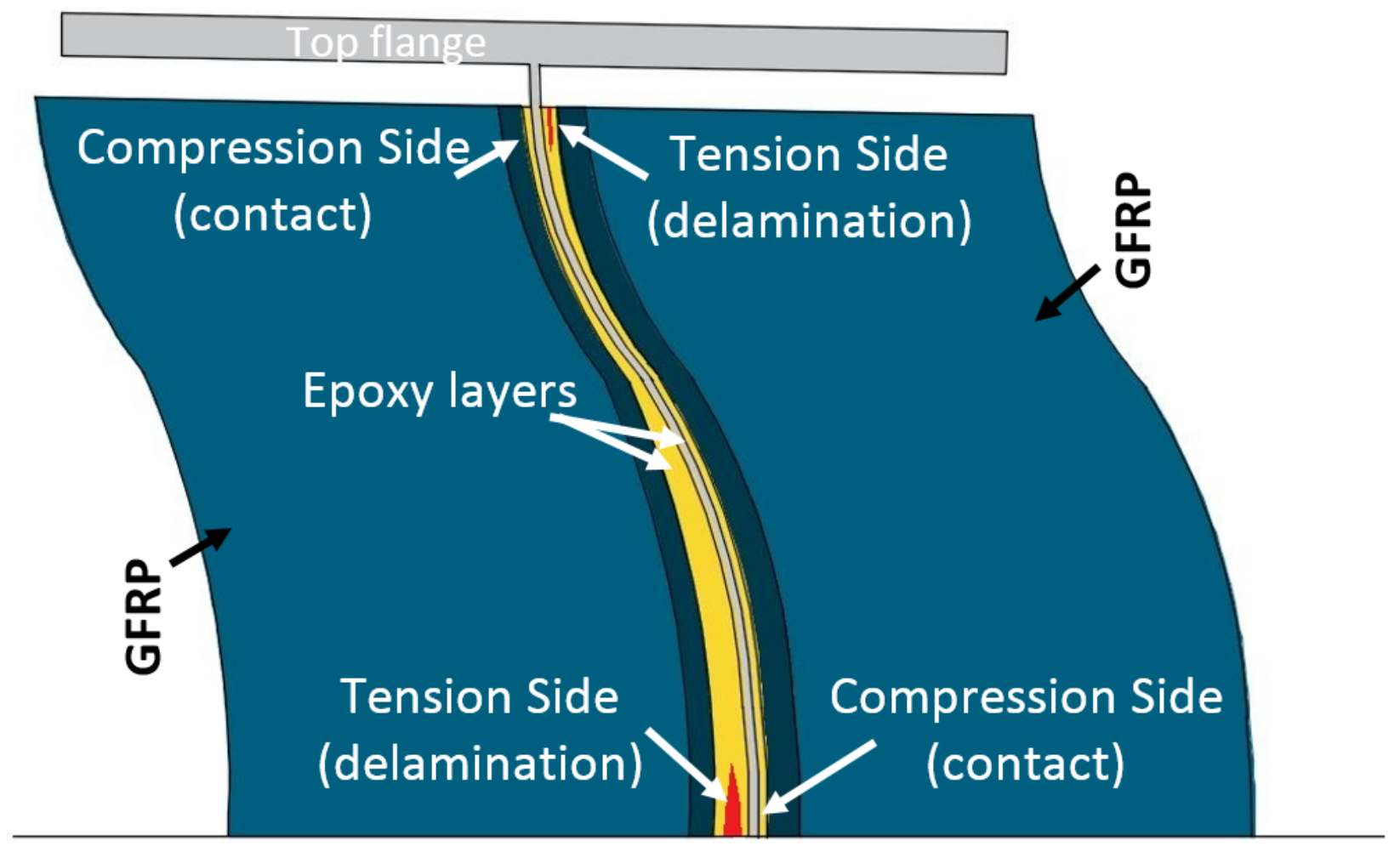

Fig. 5FRP stiffener failure mechanism at adhesive level (not scaled sketch) 
Effect of Initial Panel Slenderness on Efficiency of Strengthening-By-Stiffening using FRP for Shear Deficient Steel Beams

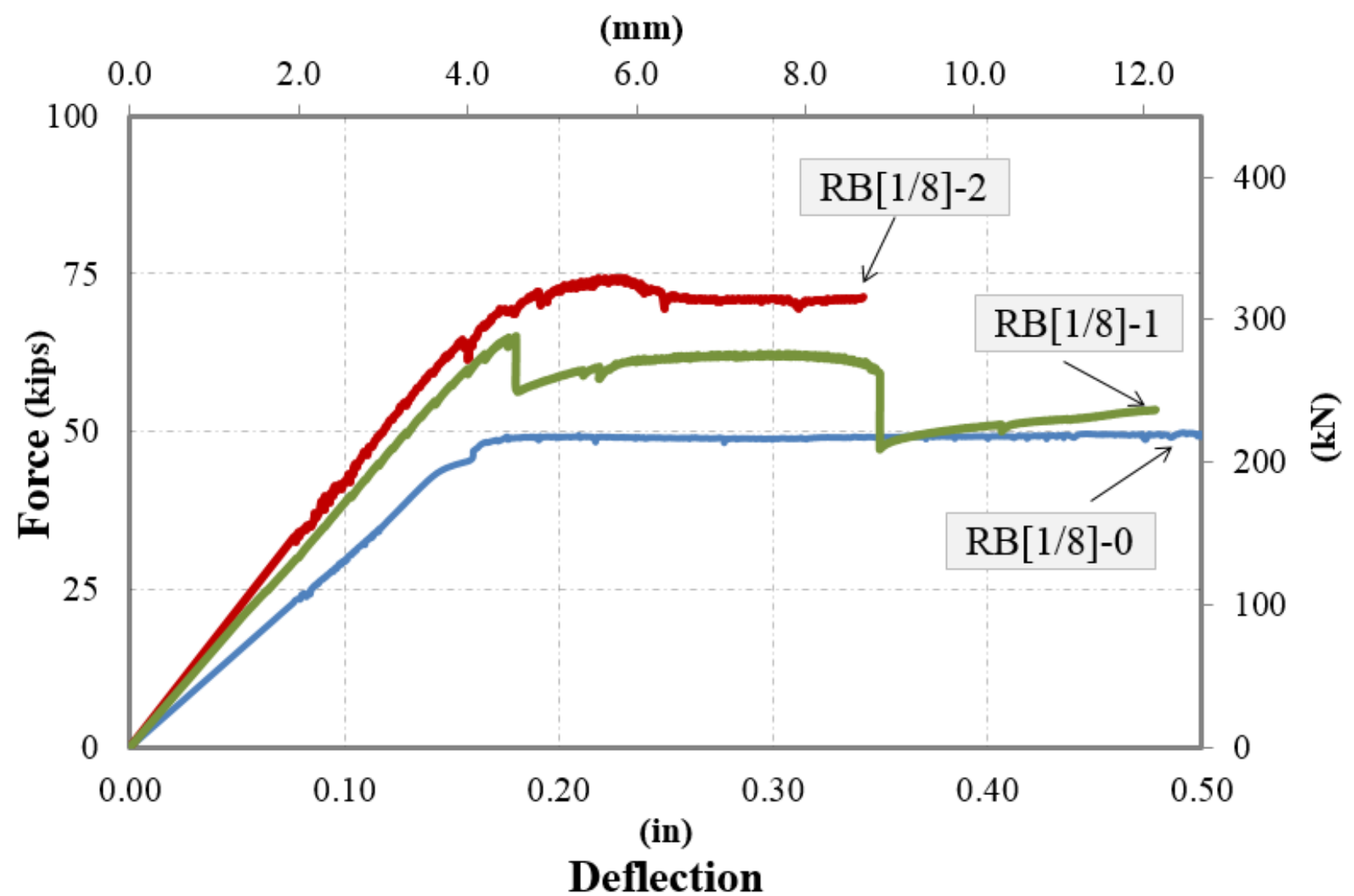

Fig. 6Load vs deflection plot of RB[1/8]-0, RB[1/8]-1, RB[1/8]-2 beams 
Effect of Initial Panel Slenderness on Efficiency of Strengthening-By-Stiffening using FRP for Shear Deficient Steel Beams

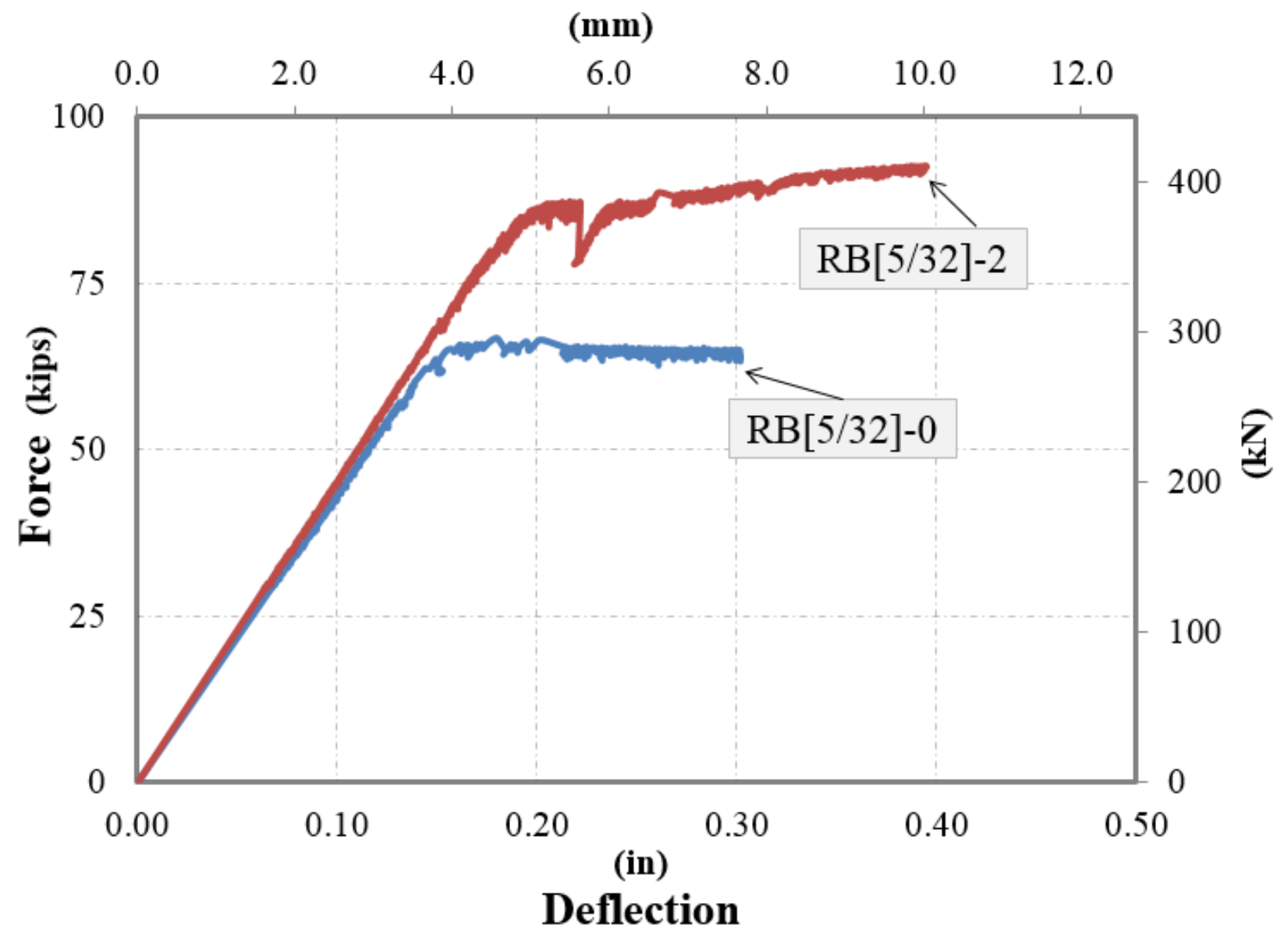

Fig. 7Load vs deflection plot of RB[5/32]-0, RB[5/32]-2 beams 


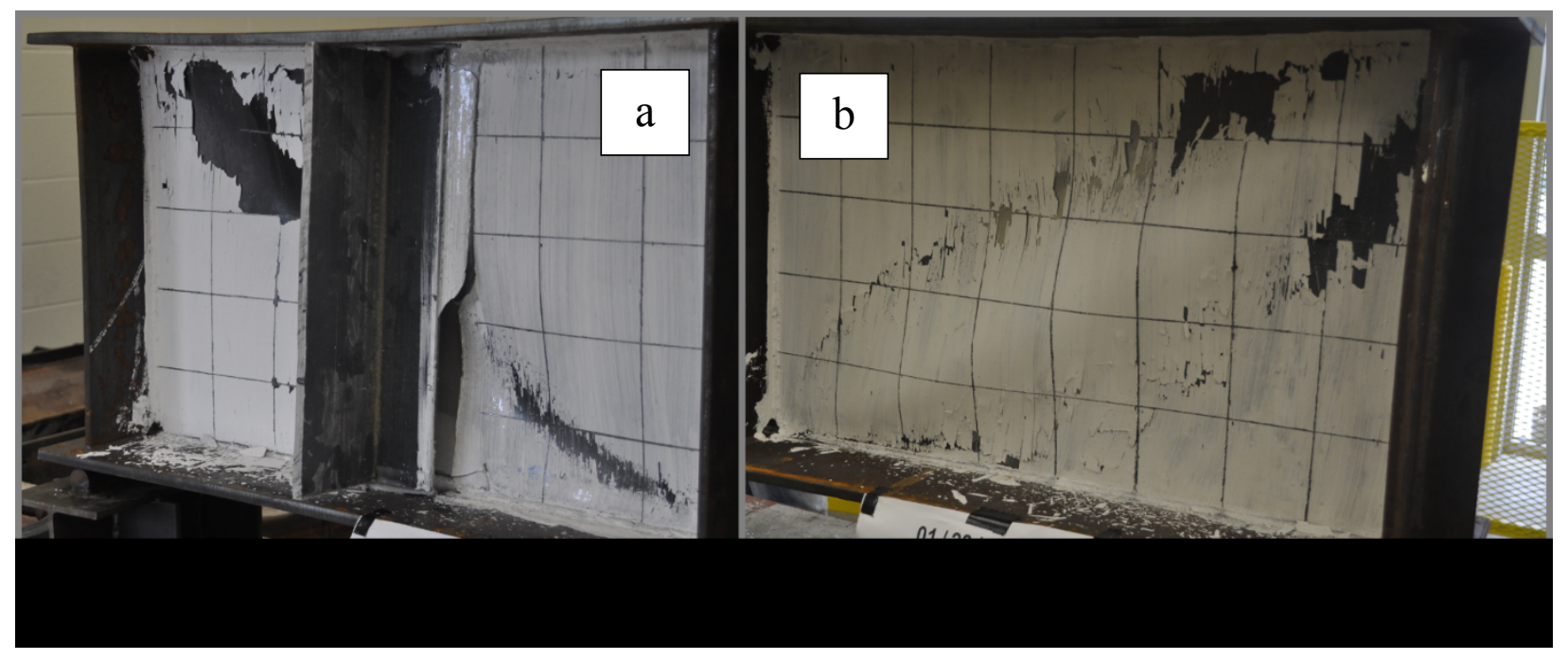

Fig. 8 Failure mode for Specimen RB[1/8]-1 (a) front - (b) back 
Effect of Initial Panel Slenderness on Efficiency of Strengthening-By-Stiffening using FRP for Shear Deficient Steel Beams

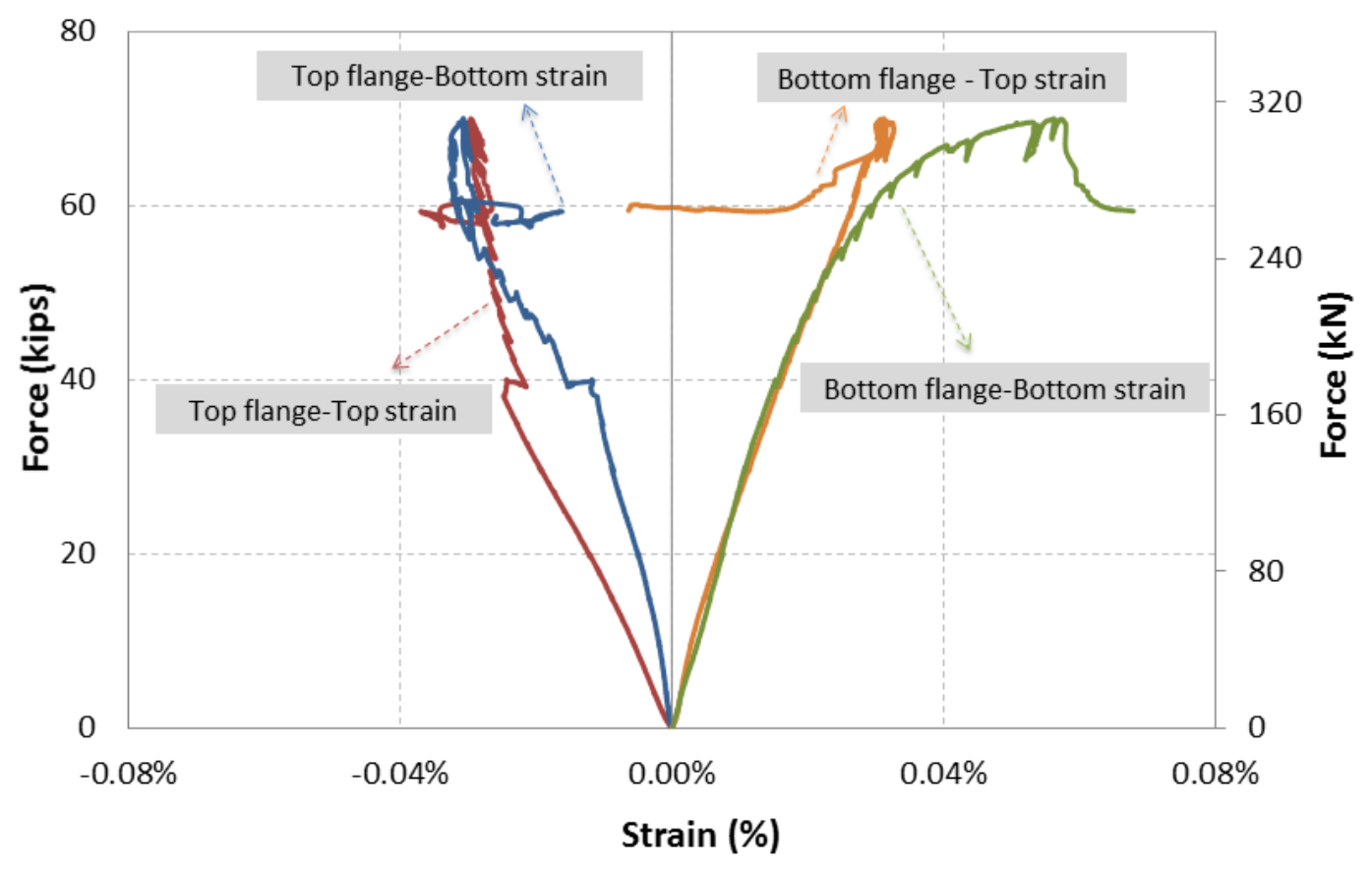

Fig. 9Strain readings of $S B[1 / 8]-1$ at the top and bottom flanges 
Effect of Initial Panel Slenderness on Efficiency of Strengthening-By-Stiffening using FRP for Shear Deficient Steel Beams

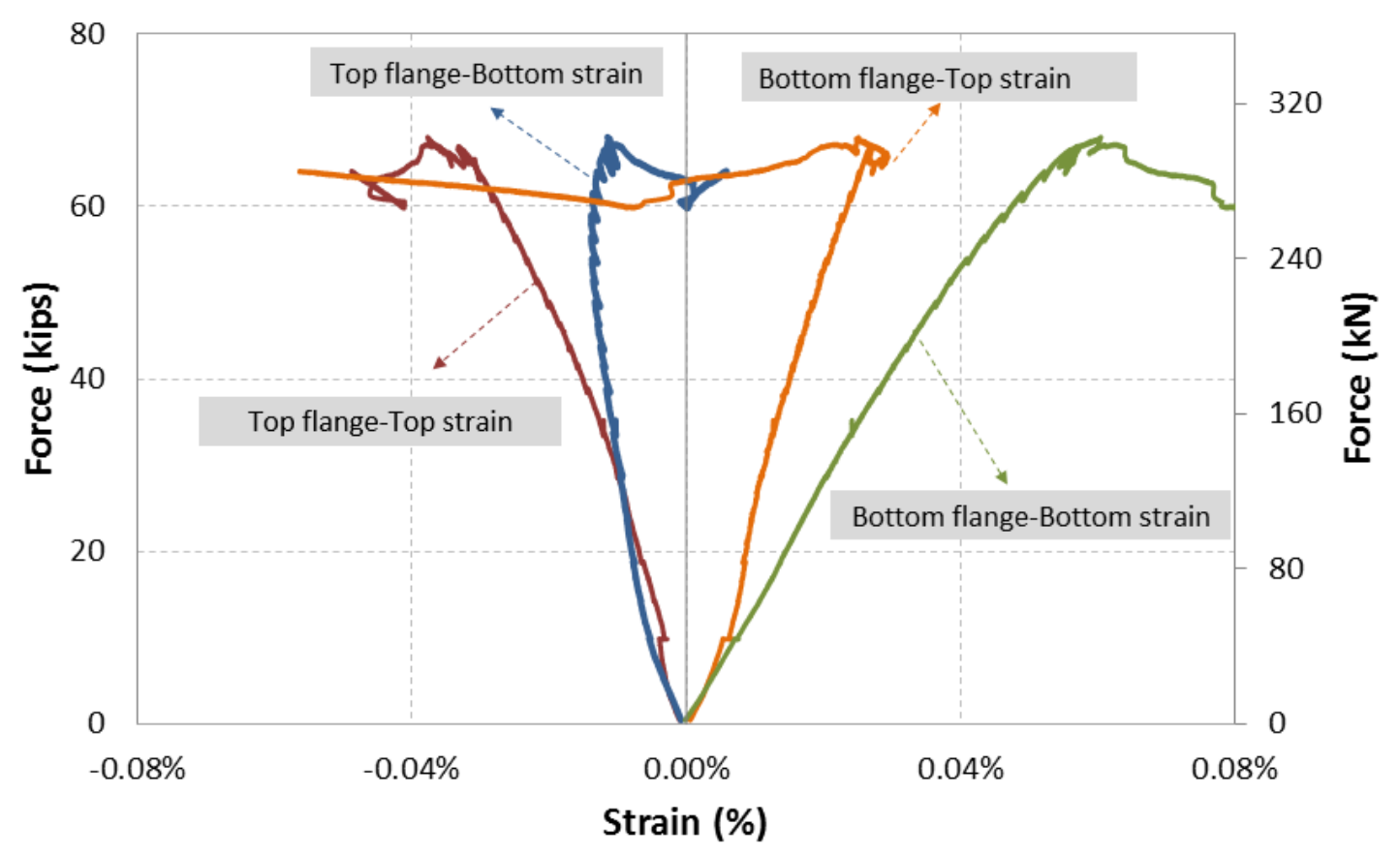

Fig. 10Strain readings of $\mathrm{RB}[1 / 8]-2$ at the top and bottom flanges 
Effect of Initial Panel Slenderness on Efficiency of Strengthening-By-Stiffening using FRP for Shear Deficient Steel Beams

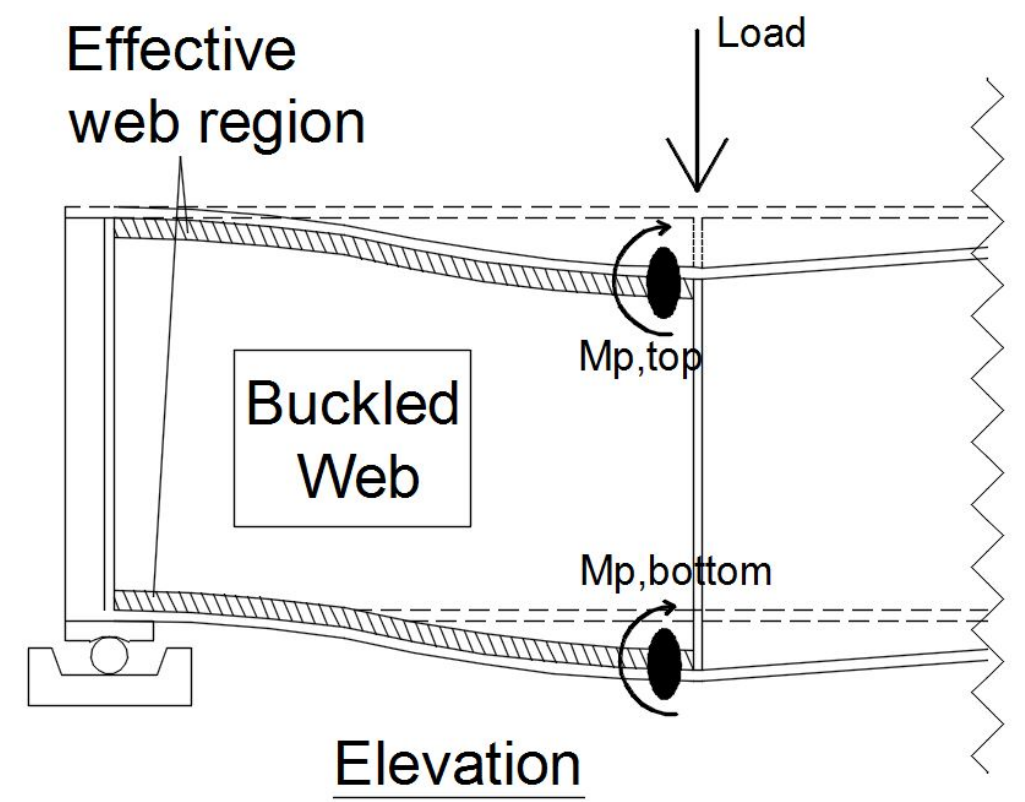

Fig. 11Sway Frame Action and Local Plastic Moment Locations 